\title{
Silencing microRNA-29b-3p expression protects human trabecular meshwork cells against oxidative injury via upregulation of RNF138 to activate the ERK pathway
}

\author{
HETING LIU $^{1}$, YANGHUI XIU ${ }^{2}$, QING ZHANG ${ }^{1}$, YUXIN XU ${ }^{1}$, QIANQIAN WAN ${ }^{1}$ and LIMING TAO ${ }^{1}$ \\ ${ }^{1}$ Department of Ophthalmology, The Second Hospital of Anhui Medical University, Hefei, Anhui 230601; \\ ${ }^{2}$ Eye Institute and Xiamen Eye Center, Affiliated Xiamen University, Xiamen, Fujian 361000, P.R. China
}

Received November 23, 2020; Accepted February 26, 2021

DOI: $10.3892 /$ ijmm.2021.4934

\begin{abstract}
In recent years, the potential involvement of numerous microRNAs (miRNAs) in glaucoma has been widely reported. However, the role of microRNA-29b-3p (miR-29b-3p) in the pathogenesis of glaucoma remains unknown. This study aimed to explore the biological role and regulatory mechanism of miR-29b-3p in the oxidative injury of human trabecular meshwork (HTM) cells induced by $\mathrm{H}_{2} \mathrm{O}_{2}$ stimulation. By establishing a glaucoma rat model, the effects of miR-29-3p in glaucoma were detected in vivo. Our findings demonstrated that miR-29b-3p was upregulated in a glaucoma model and antagomiR-29b-3p alleviated the symptoms of glaucoma. In vitro assays revealed that miR-29b-3p expression was significantly upregulated in HTM cells with $\mathrm{H}_{2} \mathrm{O}_{2}$ stimulation. Knockdown of miR-29b-3p alleviated $\mathrm{H}_{2} \mathrm{O}_{2}$-induced oxidative injury in HTM cells by promoting cell viability, and inhibiting cell apoptosis, reactive oxygen species generation and extracellular matrix production. Subsequently, it was found that E3 ubiquitin-protein ligase RNF138 (RNF138) was a downstream target of miR-29b-3p. RNF138 expression was downregulated in HTM cells with $\mathrm{H}_{2} \mathrm{O}_{2}$ stimulation. RNF138 knockdown significantly rescued the protective effect of miR-29b-3p inhibitor on HTM cells under oxidative injury. Additionally, miR-29b-3p silencing activated the ERK pathway via upregulating RNF138. Collectively, silencing of miR-29b-3p protected HTM cells against oxidative injury by upregulation of RNF138 to activate the ERK pathway.
\end{abstract}

Correspondence to: Dr Liming Tao, Department of Ophthalmology, The Second Hospital of Anhui Medical University, 678 Furong Road, Hefei, Anhui 230601, P.R. China

E-mail: taoliming@ahmu.edu.cn

Key words: microRNA-29b-3p, E3 ubiquitin-protein ligase RNF138, ERK pathway, glaucoma, oxidative stress

\section{Introduction}

Glaucoma is a progressive optic neuropathy characterized by the damage of optic nerve and visual function, which can lead to irreversible vision loss $(1,2)$. Over 70 million individuals worldwide are affected by glaucoma (3). Elevated intraocular pressure (IOP) is the primary risk factor for glaucoma, and reducing IOP is an effective therapy for glaucoma $(4,5)$. The high IOP results from the imbalance of the aqueous humor inflow and outflow. Trabecular meshwork (TM), responsible for the extracellular matrix (ECM) production, plays an important role in aqueous humor outflow $(6,7)$. It has been suggested that the excessive deposition of ECM in TM cells causes the resistance of outflow $(8,9)$. Thus, it is of great significance to clarify the potential mechanism underlying ECM deposition in TM cells for glaucoma treatment.

MicroRNAs (miRNAs/miRs), a family of small non-coding RNAs with $\sim 22$ nucleotides in length, play crucial roles in the regulation of posttranscriptional gene silencing $(10,11)$. miRNAs serve as key regulators in various cellular processes, including cell growth, metabolism, migration and apoptosis in a number of human diseases $(12,13)$. Previously, increasing number of miRNAs are reported to be involved in the progression of glaucoma. miR-21a-5p exerts neuroprotective effects on mesenchymal stem cells by targeting programmed cell death protein 4 in acute glaucoma (14). miR-1298 protects human trabecular meshwork (HTM) cells against chronic oxidative injury by targeting eukaryotic translation initiation factor 4E type 3 (15). miR-483-3p targeting Smad4 has a suppressive effect on ECM production in HTM cells (16). Moreover, the functions of miR-29b-3p in a variety of diseases have been elucidated. For example, miR-29b-3p expression is upregulated in patients with congenital heart disease and miR-29b-3p silencing promotes cardiomyocyte proliferation via targeting NOTCH2 (17). miR-29b-3p contributes to the inflammatory response of human bronchial epithelial cells stimulated by particulate matter by suppressing the AMPK pathway (18). miR-29b-3p promotes the apoptosis of retinal microvascular endothelial cells via downregulating sirtuin-1 in an in vitro model of diabetic retinopathy (19). 
The aim of the present study was to investigate the role and regulatory mechanism of miR-29b-3p in HTM cells under oxidative stress in order to find potential novel therapeutic targets for glaucoma treatment.

\section{Materials and methods}

Laboratory animals. A total of 18 Wistar rats ( 8 weeks old, male, weighing 220 260 g) were provided by Beijing Vital River Laboratory Animal Technology Co., Ltd. Before the experiments, all rats received 1 week of adaptive feeding, with four to six rats in each cage. Rats were raised with ad libitum access to water and food in a temperature-controlled room $\left(22 \pm 2^{\circ} \mathrm{C}\right)$ with a $12 \mathrm{~h}$ light/dark cycle and a relative humidity of 40-60\%. All animal studies were performed following the animal guidelines of the International Association for the Study of Pain (20), and approved by the Ethics Committee of the Second Hospital of Anhui Medical University (approval no. 2019-051; Hefei, China).

Establishment of glaucoma models and IOP measurement. For establishment of glaucoma models, rats were anesthetized with intraperitoneal injection of 3\% pentobarbital sodium (30 mg/kg; Sigma-Aldrich; Merck KGaA). The right eyes of rats underwent operation. $0.1 \mathrm{ml}$ aqueous fluid was extracted from the anterior temporal horn of iris through a cannula, and 14 rats were slowly injected with $3 \%$ compound carbomer solution through the cannula, while 4 rats were treated with the same amount of normal saline. After administration, all rats were treated with $0.5 \%$ moxifloxacin three times a day for 3 days. IOP measurement was operated using a tonometer (Mentor O\&O, Inc.). IOP was measured at $10 \mathrm{AM}$ and 10 PM every day. A mean IOP was calculated from five automatically averaged measurements. A total of 12 rats with high IOP $>30 \mathrm{mmHg}$ were chosen. When the steadily increased IOP was achieved, four glaucoma model rats were injected with $5 \mu \mathrm{l}$ antagomiR-29b-3p (Shanghai GenePharma Co., Ltd.), whereas the control rats were injected with $5 \mu \mathrm{l}$ antagomiR-negative control (NC) (Shanghai GenePharma Co., Ltd.). Rats were anesthetized with an intraperitoneal injection of $30 \mathrm{mg} / \mathrm{kg}$ pentobarbital sodium and were sacrificed by decapitation.

Hematoxylin and eosin $(H \& E)$ staining. The right eyeballs of rats were isolated after the rats were sacrificed, and then fixed in $4 \%$ paraformaldehyde for $24 \mathrm{~h}$ at room temperature. The cornea was incised along the sclera and the iris and lens were removed $30 \mathrm{~min}$ later. The retinal tissues were paraffin-embedded and cut into $5-\mu \mathrm{m}$ sections for $\mathrm{H} \& \mathrm{E}$ staining assay. The sections were stained with hematoxylin for $2 \mathrm{~min}$ and stained with eosin for $10 \mathrm{~min}$ at room temperature (Beijing Zhongshan Golden Bridge Biotechnology Co., Ltd.). After dehydration with gradient alcohol, the sections were sealed using neutral resin. The morphology of retinal tissues was observed under a light microscope at x 20 magnification (Olympus Corporation), and the results were quantified using ImageJ software (version 1.46; National Institutes of Health). The mean value was obtained from five randomly selected fields.
HTM cell culture and treatment. HTM cells (ScienCell Research Laboratories, Inc.) were cultured in Dulbecco's modified Eagle's medium (DMEM) containing 15\% fetal bovine serum, $2 \mathrm{mM}$ L-glutamine, $0.05 \%$ gentamicin, $1 \mathrm{ng} / \mathrm{ml}$ FGF-2 and $0.25 \mu \mathrm{g} / \mathrm{ml}$ amphotericin B (all from ScienCell Research Laboratories, Inc.) at $37^{\circ} \mathrm{C}$ with $5 \% \mathrm{CO}_{2}$. The medium was replaced every day when the culture reached $70 \%$ confluence. To induce oxidative stress, cells were incubated in DMEM supplemented with $\mathrm{H}_{2} \mathrm{O}_{2}$ (Beyotime Institute of Biotechnology) at concentrations of $100,200,300,400 \mu \mathrm{M}$ for $24 \mathrm{~h}$ after reaching $85 \%$ confluence.

Cell transfection. The mature miR-29b-3p mimic (for miR-29b-3p overexpression) and its NC mimic, miR-29b-3p inhibitor (for miR-29b-3p silencing) and its $\mathrm{NC}$ inhibitor, small interfering (si)RNA against E3 ubiquitin-protein ligase RNF138 (RNF138; siRNF138, for RNF138 knockdown) and its NC (si-NC) were constructed by Shanghai GenePharma Co., Ltd. The following sequences were included in the present study: NC mimic, 5'-CAGUACUUUUGUGUAGUACAAA-3'; miR-29b-3p mimic, 5'-UAGCACCAUUUGAAAUCAGUG U-3'; NC inhibitor, 5'-UUUGUACUACACAAAAGUACUG-3'; miR-29b-3p inhibitor, 5'-UAGCACCAUUUGAAAUCAGUG U-3'; si-NC, 5'-UAGAAGUUAACUUCACAGCAU-3'; and SiRNF138, 5'-ACAUUUUCUACAGAAAACGUG-3'. HTM cells were seeded into the 6 -well plates at a density of $1 \times 10^{6}$ and subsequently transfected with miR-29b-3p mimic/inhibitor (50 nM), NC mimic/inhibitor (50 nM), siRNF138 and si-NC (100 ng) using Lipofectamine ${ }^{\circledR} 3000$ (Invitrogen; Thermo Fisher Scientific, Inc.) for $48 \mathrm{~h}$. The HTM cells were assigned into the following groups: i) Control group, cells without $\mathrm{H}_{2} \mathrm{O}_{2}$ stimulation; ii) $\mathrm{H}_{2} \mathrm{O}_{2}$ group, cells with $300 \mu \mathrm{M} \mathrm{H}_{2} \mathrm{O}_{2}$ stimulation; iii) $\mathrm{H}_{2} \mathrm{O}_{2}+\mathrm{NC}$ group, cells with $300 \mu \mathrm{M} \mathrm{H}_{2} \mathrm{O}_{2}$ stimulation $+\mathrm{NC}$; iv) $\mathrm{H}_{2} \mathrm{O}_{2}+$ miR-29b-3p mimic group, cells with $300 \mu \mathrm{M} \mathrm{H}_{2} \mathrm{O}_{2}$ stimulation + miR-29b-3p mimic; v) $\mathrm{H}_{2} \mathrm{O}_{2}$ + miR-29b-3p inhibitor group, cells with $300 \mu \mathrm{M} \mathrm{H}_{2} \mathrm{O}_{2}$ stimulation + miR-29b-3p inhibitor; vi) $\mathrm{H}_{2} \mathrm{O}_{2}+$ siRNF138 group, cells with $300 \mu \mathrm{M} \mathrm{H}_{2} \mathrm{O}_{2}$ stimulation + siRNF138; and v) $\mathrm{H}_{2} \mathrm{O}_{2}$ + miR-29b-3p inhibitor + siRNF138 group, cells with $300 \mu \mathrm{M}$ $\mathrm{H}_{2} \mathrm{O}_{2}$ stimulation + miR-29b-3p inhibitor + siRNF138. The time interval between transfection and subsequent experimentation was $48 \mathrm{~h}$.

Reverse transcription quantitative polymerase chain reaction ( $R T$ - $q P C R)$. TRIzol reagent (Invitrogen; Thermo Fisher Scientific, Inc.) was employed for the extraction of total RNA from HTM cells. First-strand cDNA synthesis was performed using M-MLV reverse transcriptase (Invitrogen; Thermo Fisher Scientific, Inc.), according to the manufacturer's protocol. qPCR was conducted using the TaqMan ${ }^{\mathrm{TM}}$ Universal Master Mix II (Applied Biosystems; Thermo Fisher Scientific, Inc.) in 7500 Fast Real-Time PCR System (Applied Biosystems; Thermo Fisher Scientific, Inc.). For quantification of miRNAs, cDNA was obtained from $3 \mu \mathrm{g}$ RNA using a specific stem-loop primer. The $2^{-\Delta \Delta \mathrm{Cq}}$ method (21) was used for quantification and miRNA expression was normalized to U6, while GAPDH acted as the endogenous reference gene for mRNA. The following primers were used for RT-qPCR: miR-29b-3p forward, 5'-UAGCACCAUUUGAAAUC-3' and reverse, 5'-GTGCAGGTCCGAGGT-3'; U6 forward, 5'-CGC 
TTCGGCAGCACATATAC-3' and reverse, 5'-TTCACGAAT TTGCGTGTCAT-3'; RNF138 forward, 5'-TATAGTTCTGGC TCTCTGAA-3' and reverse, 5'-CTGACTTGGGTAAATGCT CAAT-3'; collagen $\alpha-1(\mathrm{I})$ chain (COL1A1) forward, 5'-CCT GTCTGCTTCCTGTAAAC-3' and reverse, 5'-ATGTTCGGT TGGTCAAAGATAAAT-3'; collagen $\alpha-2$ (I) chain (COL1A2) forward, 5'-CAGTCGTATGCGCGTATAGC-3' and reverse, 5'-CGTAGTCGTAGCTAGCTAGAGA-3'; and GAPDH forward, 5'-GGAGCGAGATCCCTCCAAAAT-3' and reverse, 5'-GGCTGTTGTCATACTTCTCATGG-3'. The thermocycling conditions used were as follows: $94^{\circ} \mathrm{C}$ for $5 \mathrm{~min}$; followed by 40 cycles of $94^{\circ} \mathrm{C}$ for $1 \mathrm{~min}, 56^{\circ} \mathrm{C}$ for $1 \mathrm{~min}$ and $72^{\circ} \mathrm{C}$ for $1 \mathrm{~min}$.

Western blot analysis. The treated HTM cells were collected and washed with pre-cooling PBS. After centrifugation at $600 \mathrm{x}$ g for $5 \mathrm{~min}$ at $4^{\circ} \mathrm{C}$, the cells were lysed with radio immunoprecipitation assay buffer (Sigma-Aldrich; Merck KGaA). Then, cell lysates were centrifuged at $12,000 \mathrm{x}$ g for $12 \mathrm{~min}$ at $4^{\circ} \mathrm{C}$, followed by measurement of proteins in the supernatant using the BCA protein assay (Pierce; Thermo Fisher Scientific, Inc.). After proteins ( $20 \mu \mathrm{g}$ per lane) were separated via sodium dodecyl sulfate-polyacrylamide gel electrophoresis on $10 \%$ gel, proteins were transferred to polyvinylidene difluoride membranes. Afterwards, the membranes were blocked with $5 \%$ non-fat dry milk at $4{ }^{\circ} \mathrm{C}$ overnight, and incubated with the following primary antibodies at $4^{\circ} \mathrm{C}$ overnight: Anti-RNF138 (cat. no. K107111P; 1:5,000; Beijing Solarbio Science \& Technology Co., Ltd.), anti-Bcl-2 (cat. no. ab185002; 1:1,000; Abcam), anti-Bax (cat. no. ab32503; 1:1,000; Abcam), anti-COL1A1 (cat. no. ab210966; 1:1,000; Abcam), anti-COL1A2 (cat. no. ab96723; 1:1,000; Abcam), anti-ERK (cat. no. ab115799; 1:1,000; Abcam), anti-phosphorylated (p)-ERK (cat. no. ab214036; 1:1,000; Abcam) and anti- $\beta$-actin (cat. no. ab179467; 1:1,000; Abcam). The membranes were subsequently cultured with the corresponding secondary antibodies (cat. no. ab205718; 1:5,000; Abcam) for $1.5 \mathrm{~h}$ at room temperature. The proteins were detected using the chemiluminescence detection (ECL Plus; Pierce; Thermo Fisher Scientific, Inc.). Semi-quantification was performed using ImageJ software (version 1.46; National Institutes of Health).

3-(4,5-Dimethylthiazol-2-yl)-2,5-diphenyltetrazolium bromide (MTT) assay. HTM cell viability was assessed using an MTT assay. After transfection and $\mathrm{H}_{2} \mathrm{O}_{2}$ stimulation, cells $(1,000$ cells per well) were seeded in the 96-well plates, followed by incubation with $50 \mu \mathrm{l}$ MTT (5 mg/ml; Sigma-Aldrich; Merck KGaA) for $4 \mathrm{~h}$. Then, $150 \mu \mathrm{l}$ dimethylsulfoxide (Sigma-Aldrich; Merck $\mathrm{KGaA}$ ) was used to dissolve the formazan deposited in cells for $10 \mathrm{~min}$. The absorbance at $490 \mathrm{~nm}$ was detected using a microplate reader (Bio-Rad Laboratories, Inc.).

Cell apoptosis assay. After transfection and $\mathrm{H}_{2} \mathrm{O}_{2}$ stimulation, HTM cells were washed in PBS and digested using EDTA-free trypsin. Then, cells were suspended in binding buffer at a density of $1 \times 10^{6}$ cells $/ \mathrm{ml}$. Following which, $5 \mu \mathrm{l}$ Fluorescein isothiocyanate-labeled Annexin V and $100 \mathrm{ng}$ propidium iodide were added to the $500 \mu 1$ suspended cells, followed by incubation for $15 \mathrm{~min}$ at room temperature in the dark. Cell apoptosis was determined using the Attune ${ }^{\mathrm{TM}}$ NxT Flow Cytometer (Invitrogen; Thermo Fisher Scientific, Inc.) and the apoptosis rate was analyzed with FlowJo software (version 10.0; FlowJo LLC). Apoptosis rate $=$ apoptosis rate in quadrant $(\mathrm{Q}) 2+$ apoptosis rate in $\mathrm{Q} 3$.

Detection of reactive oxygen species (ROS). ROS levels in HTM cells were examined using a ROS assay kit (cat. no. S0033M; Beyotime Institute of Biotechnology). After transfection and $\mathrm{H}_{2} \mathrm{O}_{2}$ stimulation, HTM cells were washed in PBS and subsequently cultured in DMEM containing $10 \mu \mathrm{M}$ 2,7-dichlorodihydrofluorescein diacetate (DCFHDA) for 20 min at $37^{\circ} \mathrm{C}$. After washing with PBS twice, the cells were treated with $0.25 \%$ trypsin-EDTA, followed by centrifugation at $800 \mathrm{x} \mathrm{g}$ for $6 \mathrm{~min}$ at $37^{\circ} \mathrm{C}$. Then, cells were resuspended in $500 \mu \mathrm{l}$ PBS. The fluorescence intensity, regarded as ROS generation, was measured by an Infinite M200 microplate reader (485 and $525 \mathrm{~nm}$ emission).

Bioinformatics analysis. Targets of miR-29b-3p were predicted using miRanda version 3.3a (http://cbio.mskcc. org/microrna_data/miRanda-aug2010.tar.gz), microT-CDS DIANA Tools version 5.0 (http://diana.imis.athena-innovation. gr/DianaTools/index.php?r=microT_CDS/index) and RNA22 version 2.0 (https://cm.jefferson.edu/rna22/Interactive/).

Luciferase reporter assay. The wild-type (Wt) and mutated (Mut) sequences of the 3'UTR of RNF138 complementary to miR-29b-3p were subcloned into the pmirGLO-luciferase plasmids (Promega Corporation) to generate Wt RNF138 (RNF138-Wt) and Mut type RNF138 (RNF138-Mut). RNF138-Wt and RNF138-Mut reporters were co-transfected with NC or miR-29b-3p mimic into 293T cells (American Type Culture Collection) using Lipofectamine 3000. The interaction between miR-29b-3p and 3'-UTR of RNF138 was detected using a Luciferase Assay system (Promega Corporation) $48 \mathrm{~h}$ post-transfection. Relative luciferase activity was defined as the ratio of firefly luciferase activity to Renilla luciferase activity.

Statistical analysis. Data are presented as the mean \pm standard deviation of three independent experiments and analyzed using the SPSS 21.0 software (IBM Corp.). Comparisons between 2 groups were analyzed using unpaired Student's t-test, while comparisons among $\geq 3$ groups were analyzed using one-way analysis of variance. Dunnett's or Tukey's post hoc tests were used following one-way analysis of variance. $\mathrm{P}<0.05$ was considered to indicate a statistically significant difference.

\section{Results}

miR-29b-3p is upregulated in a rat glaucoma model and antagomiR-29b-3p alleviates the symptoms of glaucoma. As shown in Fig. 1A, in the control group, there was no significant difference between the mean and max IOP; however, the max IOP was significantly higher than the mean IOP in the glaucoma group. Moreover, RT-qPCR revealed a higher expression of miR-29b-3p in the glaucoma group compared with the control group (Fig. 1B). As presented in Fig. 1C, miR-29b-3p expression levels were decreased in rats following injection 

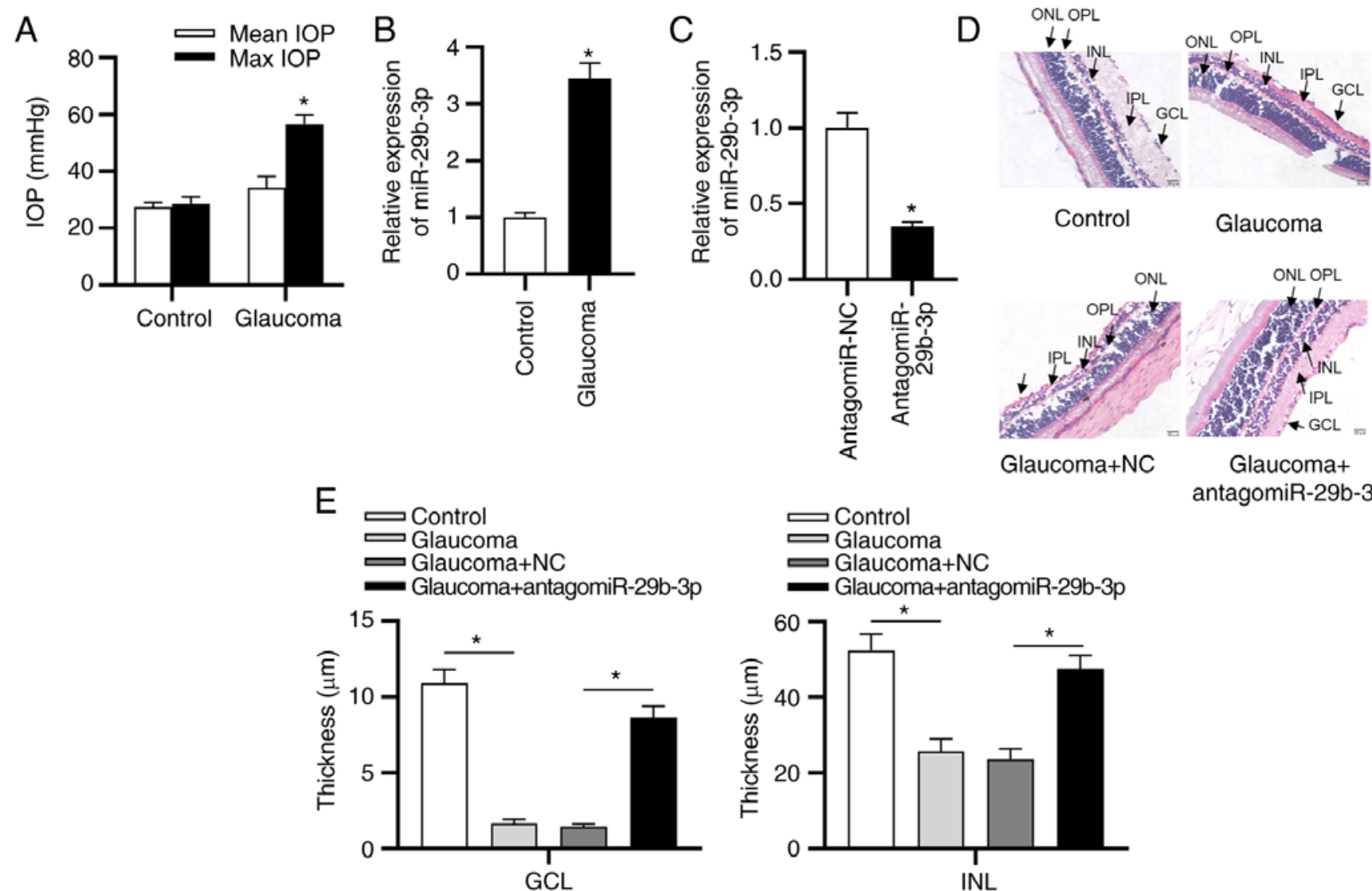

Figure 1. miR-29b-3p is upregulated in a rat glaucoma model and antagomiR-29b-3p alleviates the symptoms of glaucoma. (A) Mean and max IOP in the control and glaucoma groups. " $\mathrm{P}<0.05$ vs. control group. (B) Reverse transcription quantitative polymerase chain reaction analysis for the expression of miR-29b-3p in retinal tissues of control rats and glaucoma rats. ${ }^{*} \mathrm{P}<0.05$ vs. control group. (C) miR-29b-3p expression levels in retinal tissues of rats following injection with antagomiR-29b-3p compared with the control group. ${ }^{*} \mathrm{P}<0.05$ vs. antagomiR-NC group. (D and E) Hematoxylin and eosin staining for the morphology of retinal tissues, and the thickness of GCL and INL were quantified. " $\mathrm{P}<0.05$. miR, microRNA; IOP, intraocular pressure; GCL, ganglion cell layer; INL, inner nuclear layer; ONL, outer nuclear layer; OPL, outer plexus layer; IPL, inner plexus layer; NC, negative control.
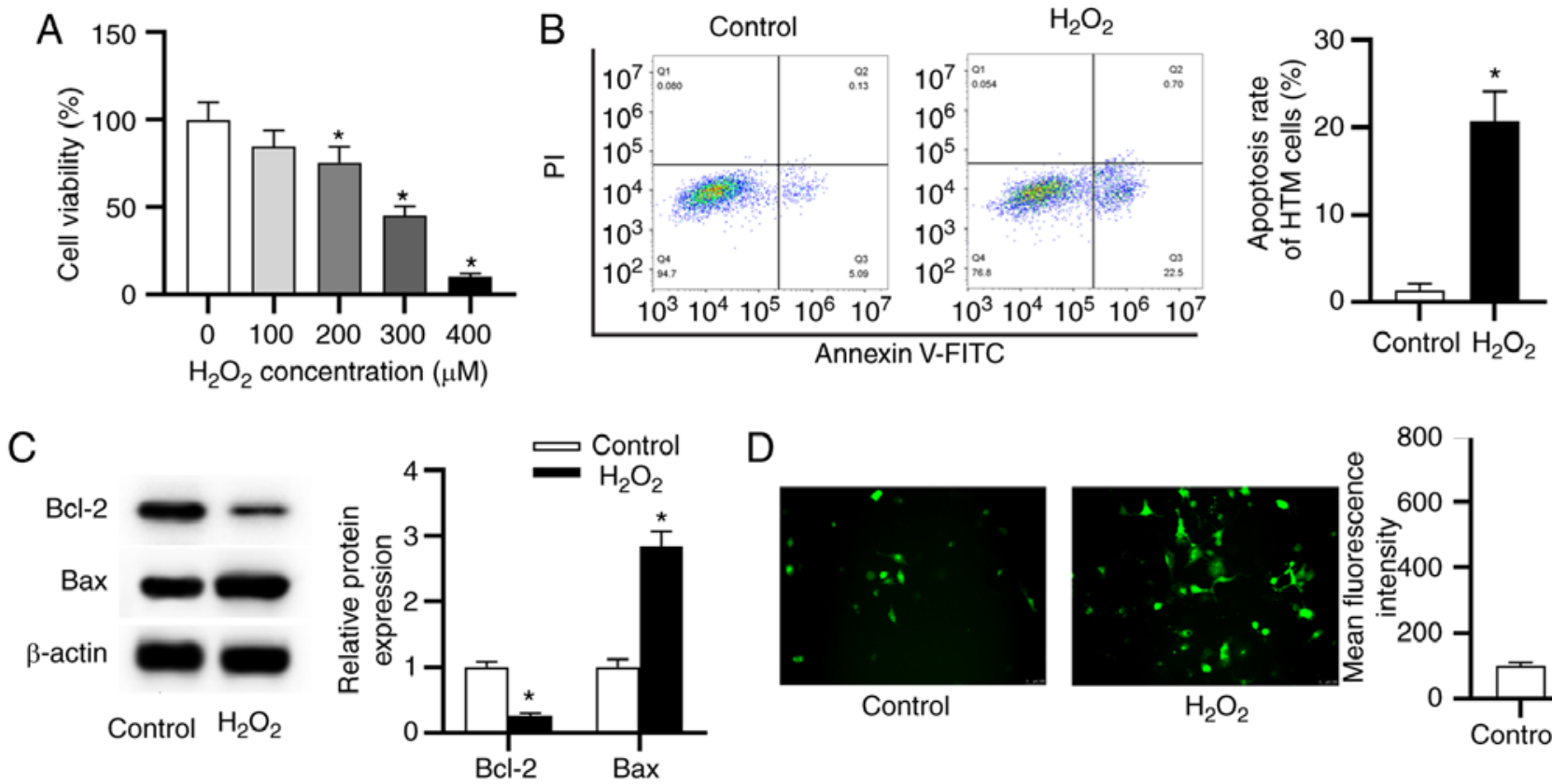

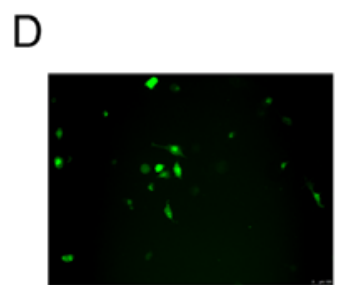

Control

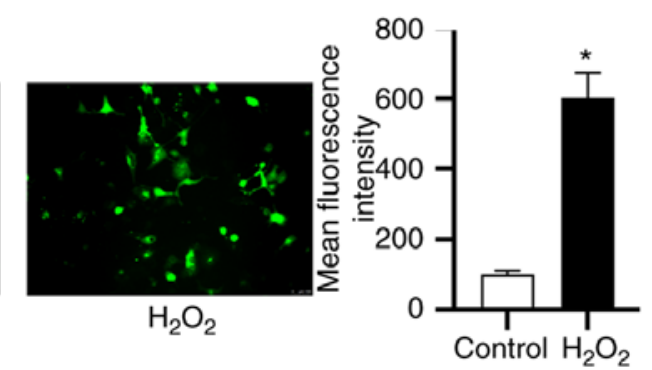

Figure 2. $\mathrm{H}_{2} \mathrm{O}_{2}$ induces oxidative damage in HTM cells. HTM cells were treated with different concentrations of $\mathrm{H}_{2} \mathrm{O}_{2}(100,200,300$ and $400 \mu \mathrm{M})$ for $24 \mathrm{~h}$, and $0 \mu \mathrm{M}$ was used as the control. (A) HTM cell viability was assessed by a 3-(4,5-dimethylthiazol-2-yl)-2,5-diphenyltetrazolium bromide assay. Then, HTM cells stimulated by $300 \mu \mathrm{M} \mathrm{H}_{2} \mathrm{O}_{2}$ for $24 \mathrm{~h}$ were used for subsequent assays. "P $<0.05$ vs. $0 \mu \mathrm{M}$. (B) The apoptotic rate of HTM cells was detected by flow cytometry analysis. (C) The levels of apoptosis-related proteins were determined by western blotting. (D) Reactive oxygen species generation was detected using 2,7-dichlorodihydrofluorescein diacetate staining. ${ }^{*} \mathrm{P}<0.05$ vs. control group. HTM, human trabecular meshwork. 

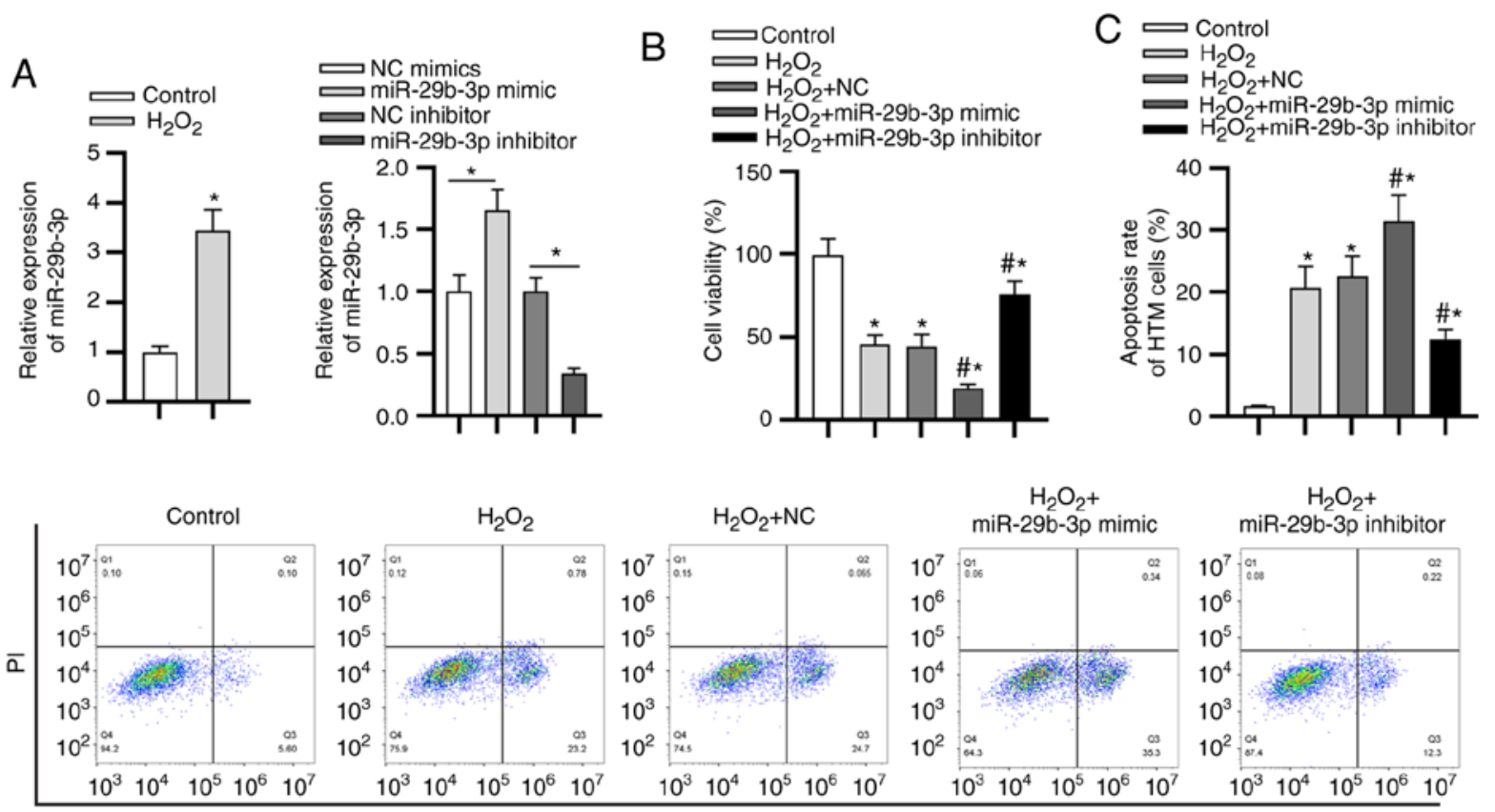

Annexin V-FITC

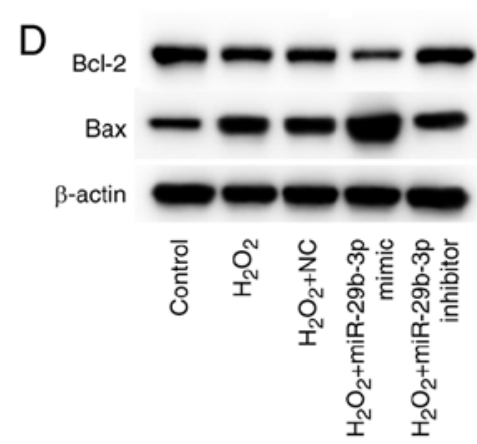

$\mathrm{E}$

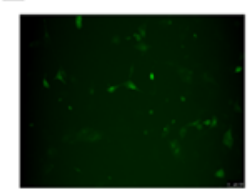

Control

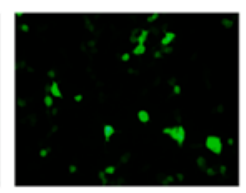

$\mathrm{H}_{2} \mathrm{O}_{2}$

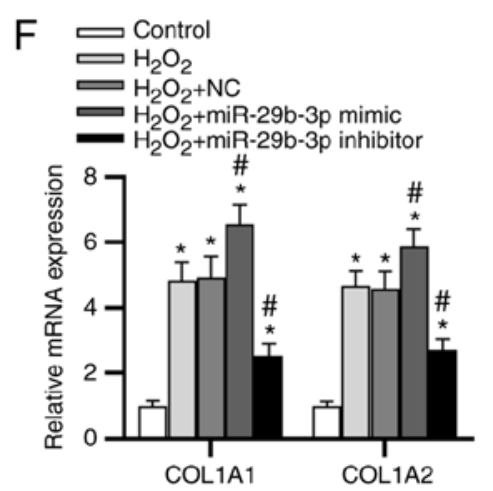

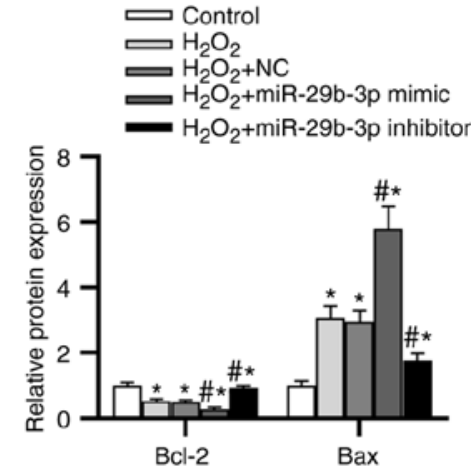

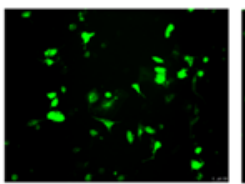

$\mathrm{H}_{2} \mathrm{O}_{2}+\mathrm{NC}$

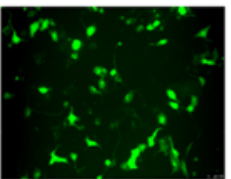

$\mathrm{H}_{2} \mathrm{O}_{2}+$ miR-29b-3p inhibitor

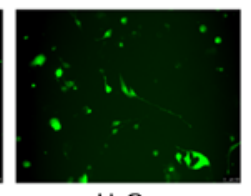

$\mathrm{H}_{2} \mathrm{O}_{2}+$

-29b-3p mimic
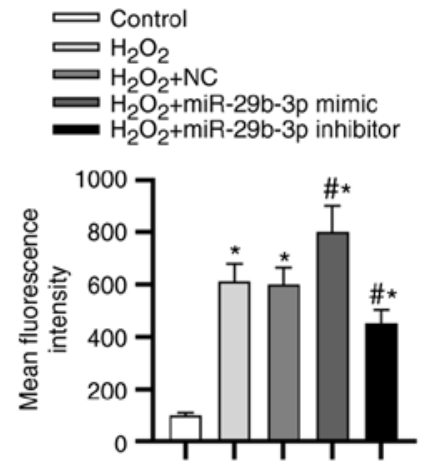

G

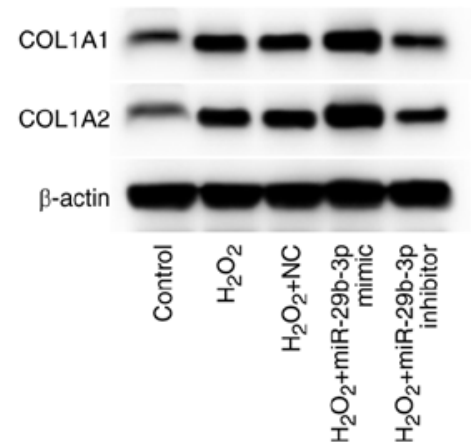

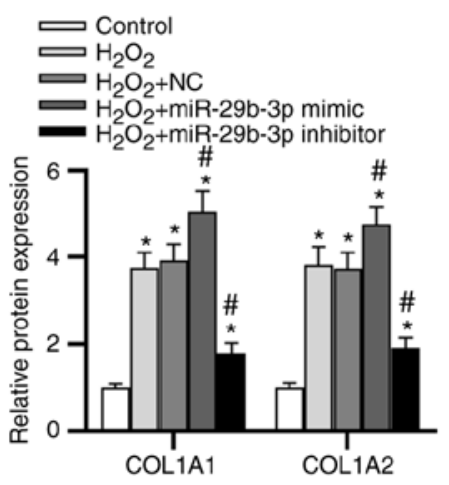

Figure 3. miR-29b-3p facilitates $\mathrm{H}_{2} \mathrm{O}_{2}$-induced injury and promotes ECM deposition, whereas silencing of miR-29b-3p exerts the opposite effects. (A) The expression of miR-29b-3p in HTM cells following different treatments was determined by RT-qPCR. (B) HTM cell viability in each group was assessed by a 3-(4,5-dimethylthiazol-2-yl)-2,5-diphenyltetrazolium bromide assay. (C) The apoptotic rate of HTM cells in each group was evaluated using flow cytometry. (D) The levels of apoptosis-related proteins in HTM cells in each group were measured by western blotting. (E) Reactive oxygen species generation in HTM cells in each group was detected by 2,7-dichlorodihydrofluorescein diacetate staining. (F) The mRNA expression of COL1A1 and COL1A2 in HTM cells was detected by RT-qPCR. (G) The protein levels of ECM-related genes in HTM cells were evaluated by western blotting. ${ }^{*} \mathrm{P}<0.05$ vs. control group; ${ }^{\prime} \mathrm{P}<0.05$ vs. $\mathrm{H}_{2} \mathrm{O}_{2}$ and $\mathrm{H}_{2} \mathrm{O}_{2}+\mathrm{NC}$ groups. miR, microRNA; HTM, human trabecular meshwork; RT-qPCR, reverse transcription quantitative polymerase chain reaction; ECM, extracellular matrix; NC, negative control; COL1A1, collagen $\alpha-1(\mathrm{I})$ chain; COL1A2, collagen $\alpha-2(\mathrm{I})$ chain. 
A

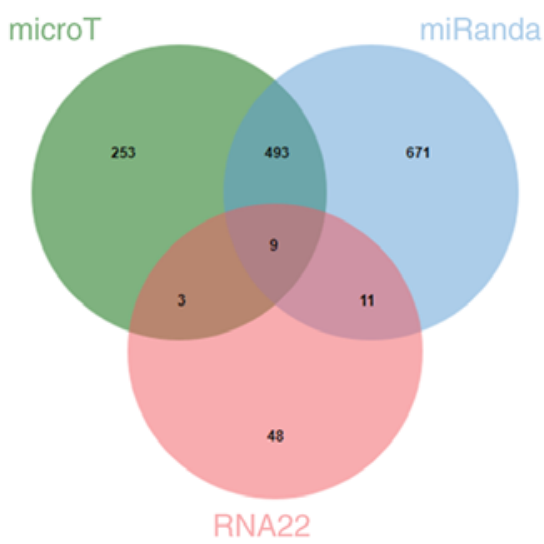

C

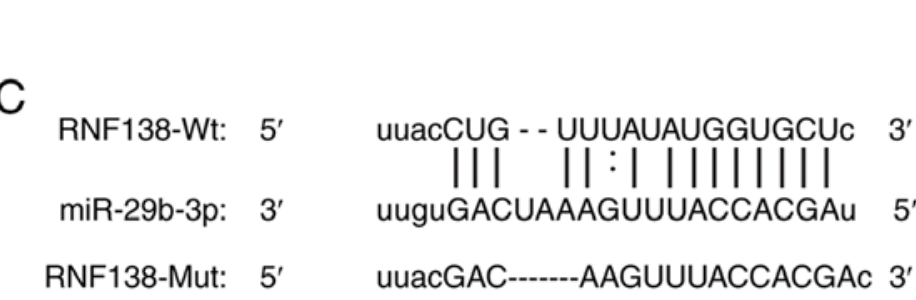

E

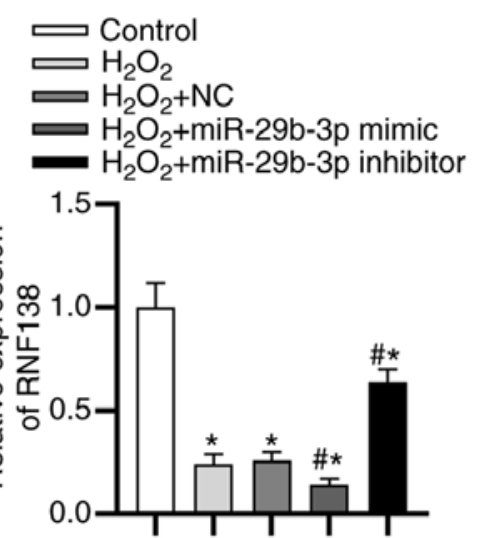

$\mathrm{F}$
B

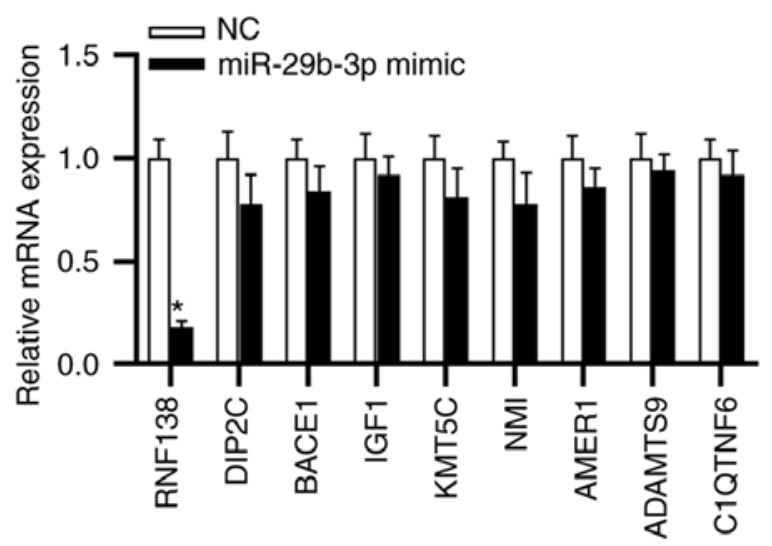

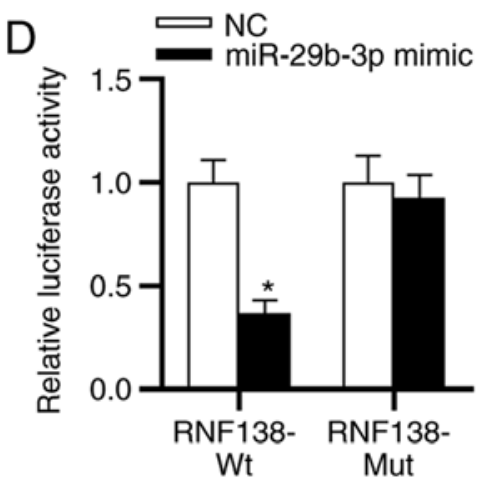

RNF138

$\beta$-actin

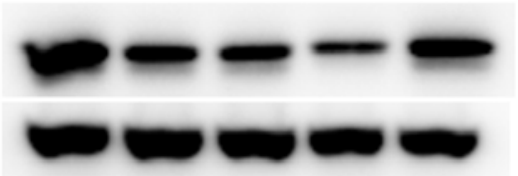

일
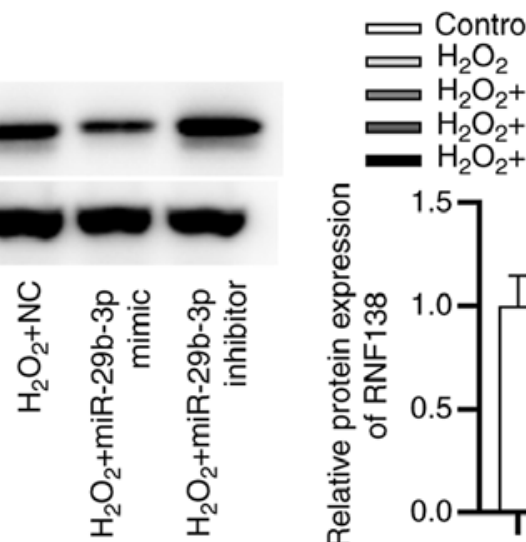$$
\rightleftharpoons \mathrm{H}_{2} \mathrm{O}_{2}+\mathrm{NC}
$$

$\mathrm{H}_{2} \mathrm{O}_{2}+$ miR-29b-3p mimic

- $\mathrm{H}_{2} \mathrm{O}_{2}+$ miR-29b-3p inhibitor

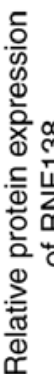

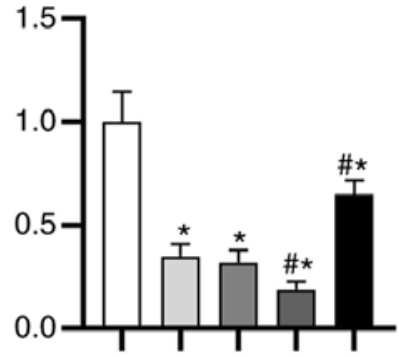

Figure 4. RNF138 is a target gene of miR-29b-3p. (A) Venn diagram showing nine mRNAs as possible targets of miR-29b-3p as predicted by microT, miRanda and RNA22 analyses. (B) RNF138 expression in miR-29b-3p mimic-transfected HTM cells was detected using RT-qPCR. (C) The predicted binding site between miR-29b-3p and RNF138. (D) Luciferase reporter assay was performed to confirm the binding ability between miR-29b-3p and RNF138. (E and F) The expression of RNF138 at the mRNA and protein levels in HTM cells of each group was determined by RT-qPCR and western blotting, respectively. ${ }^{*} \mathrm{P}<0.05$ vs. control or $\mathrm{NC}$ group; ${ }^{\#} \mathrm{P}<0.05$ vs. $\mathrm{H}_{2} \mathrm{O}_{2}$ and $\mathrm{H}_{2} \mathrm{O}_{2}+\mathrm{NC}$ groups. RNF138, E3 ubiquitin-protein ligase RNF138; miR, microRNA; HTM, human trabecular meshwork; RT-qPCR, reverse transcription quantitative polymerase chain reaction; NC, negative control; Wt, wild-type; Mut, mutant.

with antagomiR-29b-3p compared with the NC group. Next, the functions of antagomiR-29b-3p in a glaucoma model were investigated. H\&E staining revealed that the thickness of each layer of the retinal, including the outer nuclear layer (ONL), inner nuclear layer (INL) and ganglion cell layer (GCL), were significantly thinner in the glaucoma model compared with the control group (Fig. 1D and E), and transfection with antagomiR-29b-3p increased the thickness.

$\mathrm{H}_{2} \mathrm{O}_{2}$ induces oxidative damage in HTM cells. HTM cells were treated with different concentrations of $\mathrm{H}_{2} \mathrm{O}_{2}(100$, 200,300 and $400 \mu \mathrm{M}$ ) for $24 \mathrm{~h}$ and concentration of $\mathrm{H}_{2} \mathrm{O}_{2}$ at $0 \mu \mathrm{M}$ was used as the control. The data from MTT assay revealed that $100-400 \mu \mathrm{M}$ of $\mathrm{H}_{2} \mathrm{O}_{2}$ inhibited cell viability in a concentration-dependent manner compared with the control (Fig. 2A). Since $300 \mu \mathrm{M}$ of $\mathrm{H}_{2} \mathrm{O}_{2}$ decreased $>50 \%$ of cell viability, $300 \mu \mathrm{M} \mathrm{H}_{2} \mathrm{O}_{2}$ was used for induction of oxidative damage in further assays. Subsequently, the apoptosis rate and ROS generation of HTM cells were detected. Flow cytometry results showed that the $\mathrm{H}_{2} \mathrm{O}_{2}$ group exhibited a significant increase of cell apoptosis (Fig. 2B). Similarly, the reduced level of Bcl-2 (anti-apoptotic marker) and the elevated level of Bax (pro-apoptotic marker) were revealed in the $\mathrm{H}_{2} \mathrm{O}_{2}$ group (Fig. 2C), implying that the stimulation of $\mathrm{H}_{2} \mathrm{O}_{2}$ promoted 

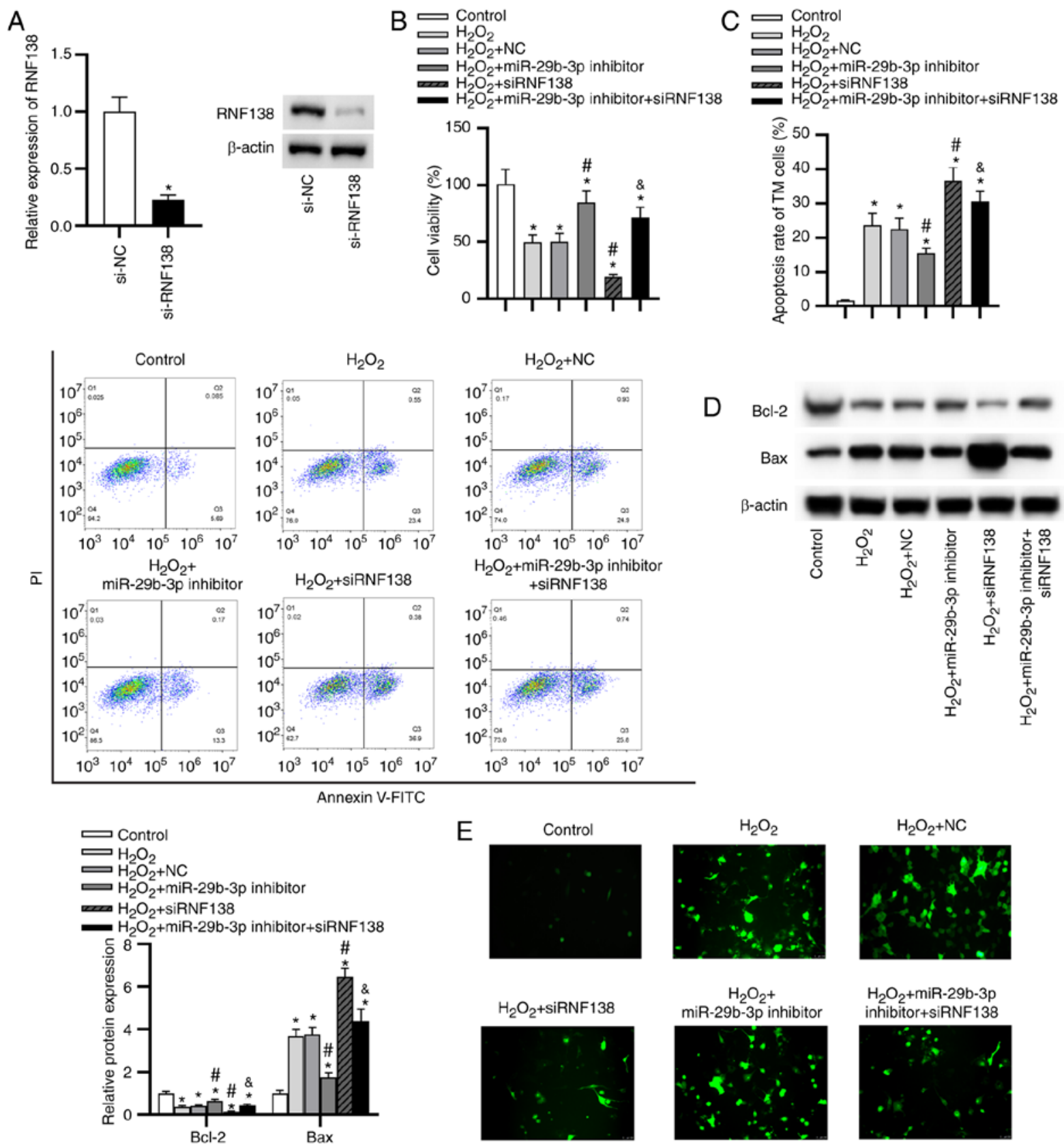

$\mathrm{H}_{2} \mathrm{O}_{2}+$ miR-29b-3p inhibitor+siRNF138
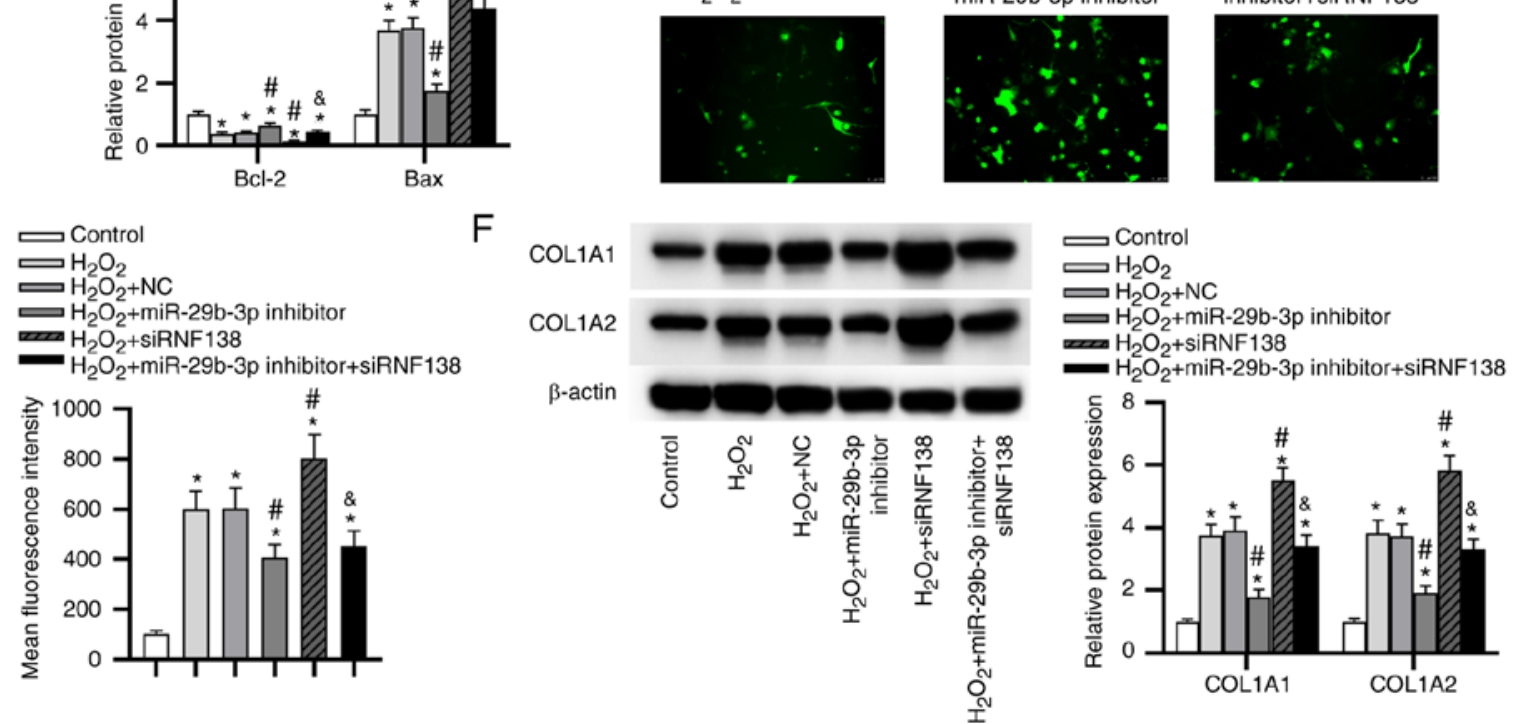

Figure 5. Silencing RNF138 expression promotes $\mathrm{H}_{2} \mathrm{O}_{2}$-induced injury and silencing of miR-29b-3p ameliorates it by upregulating RNF138. (A) The silencing efficiency of RNF138 in HTM cells was verified by reverse transcription quantitative polymerase chain reaction and western blotting. ${ }^{*} \mathrm{P}<0.05$ vs. si-NC group. (B) HTM cell viability in each group was assessed by a 3-(4,5-dimethylthiazol-2-yl)-2,5-diphenyltetrazolium bromide assays. (C) The apoptotic rate of HTM cells in each group was evaluated by flow cytometry analysis. (D) The levels of apoptosis-related proteins in HTM cells of each group were determined by western blotting. (E) Reactive oxygen species generation in HTM cells of each group was detected via 2,7-dichlorodihydrofluorescein diacetate staining. (F) The protein levels of extracellular matrix-related genes in HTM cells of each group were evaluated by western blot analysis. "P<0.05 vs. control group; ${ }^{\text {"}} \mathrm{P}<0.05$ vs. $\mathrm{H}_{2} \mathrm{O}_{2}$ and $\mathrm{H}_{2} \mathrm{O}_{2}+\mathrm{NC}$ groups; ${ }^{\&} \mathrm{P}<0.05$ vs. $\mathrm{H}_{2} \mathrm{O}_{2}+$ miR-29b-3p inhibitor group. RNF138, E3 ubiquitin-protein ligase RNF138; miR, microRNA; HTM, human trabecular meshwork; si-, small interfering RNA; NC, negative control; COL1A1, collagen $\alpha-1$ (I) chain; COL1A2, collagen $\alpha$-2(I) chain. 


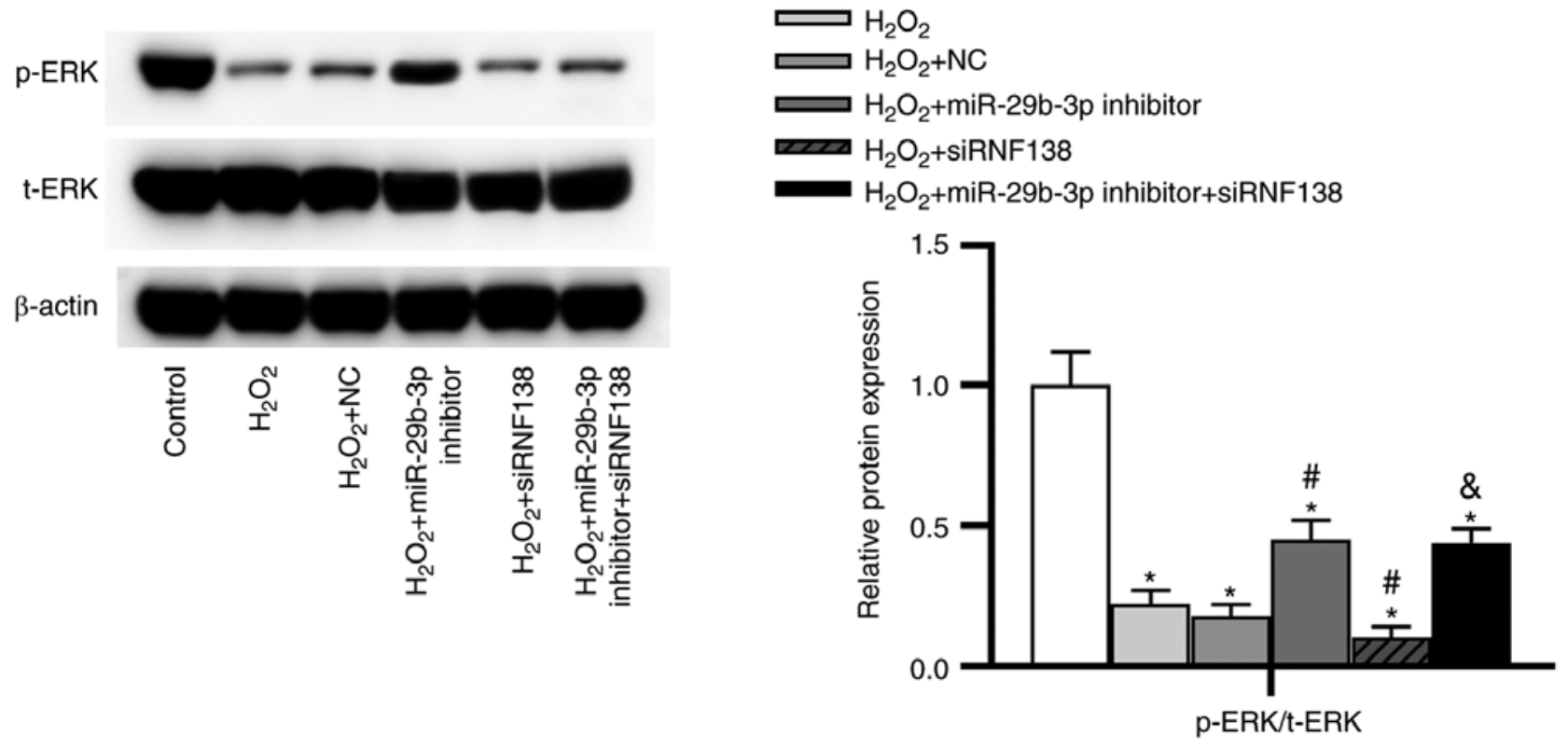

Figure 6. Downregulation of miR-29b-3p activates the ERK pathway by upregulating E3 ubiquitin-protein ligase RNF138. The expression of t-ERK and p-ERK proteins in human trabecular meshwork cells of each group was detected by western blotting and the ratio of $\mathrm{p}$-ERK/t-ERK was semi-quantified. ${ }^{*} \mathrm{P}<0.05$ vs. control group; ${ }^{\#} \mathrm{P}<0.05$ vs. $\mathrm{H}_{2} \mathrm{O}_{2}$ and $\mathrm{H}_{2} \mathrm{O}_{2}+\mathrm{NC}$ groups; ${ }^{\circledR} \mathrm{P}<0.05$ vs. $\mathrm{H}_{2} \mathrm{O}_{2}+$ miR-29b-3p inhibitor group. ERK, extracellular regulated protein kinase; miR, microRNA; NC, negative control; t-, total; p-, phosphorylated; si-, small interfering RNA.

HTM cell apoptosis. As presented in Fig. 2D, $\mathrm{H}_{2} \mathrm{O}_{2}$ stimulation increased the level of ROS compared with the control.

miR-29b-3p facilitates $\mathrm{H}_{2} \mathrm{O}_{2}$-induced injury and promotes ECM deposition while silencing of $m i R-29 b-3 p$ exerted the opposite effects. As presented in Fig. 3A, miR-29b-3p expression was at a higher level in the $\mathrm{H}_{2} \mathrm{O}_{2}$ group than in the control group. miR-29b-3p expression was increased by transfection with miR-29b-3p mimic compared with the control group. Under transfection with miR-29b-3p inhibitor, miR-29b-3p expression was $34 \%$ of the control group. MTT assay revealed that the $\mathrm{H}_{2} \mathrm{O}_{2}+$ miR-29b-3p mimic group displayed decreased cell viability, while the $\mathrm{H}_{2} \mathrm{O}_{2}+$ miR-29b-3p inhibitor group showed the opposite result (Fig. 3B). Flow cytometry showed that the apoptosis rate of HTM cells was higher in the $\mathrm{H}_{2} \mathrm{O}_{2}+$ miR-29b-3p mimic group, and lower in the $\mathrm{H}_{2} \mathrm{O}_{2}+$ miR-29b-3p inhibitor group, compared with the $\mathrm{H}_{2} \mathrm{O}_{2}+\mathrm{NC}$ group (Fig. 3C). Likewise, Bcl-2 expression was downregulated and Bax was upregulated in the $\mathrm{H}_{2} \mathrm{O}_{2}+$ miR-29b-3p mimic group, whereas the miR-29b-3p inhibitor exerted opposite effects (Fig. 3D). Furthermore, the $\mathrm{H}_{2} \mathrm{O}_{2}+$ miR-29b-3p mimic group exhibited an increased level of ROS and the $\mathrm{H}_{2} \mathrm{O}_{2}+$ miR-29b-3p inhibitor group presented the opposite trend (Fig. 3E). Additionally, the expression levels of COL1A1 and COL1A2 were determined by RT-qPCR and western blotting. As presented in Fig. 3F and G, the mRNA and protein levels of COL1A1 and COL1A2 were higher in the $\mathrm{H}_{2} \mathrm{O}_{2}$ groups than in the control group. miR-29b-3p mimics increased COL1A1 and COL1A2 levels, whereas the miR-29b-3p inhibitor decreased COL1A1 and COL1A2 levels in HTM cells under oxidative injury.

RNF138 is a target gene of $m i R-29 b-3 p$. As displayed in Fig. 4A, there were 9 potential targets of miR-29b-3p. RNF138 expression showed the most significant downregulation after miR-29b-3p overexpression using miR-29b-3p mimics (Fig. 4B). The predicted binding sites between miR-29b-3p and RNF138 are exhibited in Fig. 4C. To confirm the direct binding between miR-29b-3p and RNF138, a luciferase reporter assay was performed. The luciferase activity of RNF138-Wt was reduced by miR-29b-3p mimic, while that of RNF138-Mut reporters was not significantly altered in response to the overexpression of miR-29b-3p (Fig. 4D), indicating that RNF138 3' UTR was directly targeted by miR-29b-3p. In addition, the downregulated expression of RNF138 in HTM cells was found in the $\mathrm{H}_{2} \mathrm{O}_{2}$ group compared with control group (Fig. 4E). RNF138 expression was decreased in the $\mathrm{H}_{2} \mathrm{O}_{2}+$ miR-29b-3p mimic group and elevated in the $\mathrm{H}_{2} \mathrm{O}_{2}+$ miR-29b-3p inhibitor group (Fig. 4E). Western blotting showed that miR-29b-3p overexpression decreased the level of RFN138 protein, whereas miR-29b-3P downregulation had the opposite result (Fig. 4F).

Silencing of $\mathrm{RNF} 138$ promotes $\mathrm{H}_{2} \mathrm{O}_{2}$-induced injury and silencing of $m i R-29 b-3 p$ ameliorates it by upregulating $R N F 138$. The silencing efficiency of RNF138 was confirmed via RT-qPCR and western blotting (Fig. 5A). Knockdown of RNF138 significantly inhibited viability (Fig. 5B), promoted apoptosis (Fig. 5C and D), increased ROS level (Fig. 5E) and ECM deposition (Fig. 5F) in HTM cells under oxidative injury. Moreover, siRNF138 significantly rescued the effects of miR-29b-3p inhibitor on $\mathrm{H}_{2} \mathrm{O}_{2}$-stimulated HTM cells.

Downregulation of miR-29b-3p activates the ERK pathway by upregulating $R N F 138$. As presented in Fig. 6, the protein level of p-ERK was lower in the $\mathrm{H}_{2} \mathrm{O}_{2}$ group than in the control group. Compared with the $\mathrm{H}_{2} \mathrm{O}_{2}+\mathrm{NC}$ group, the $\mathrm{H}_{2} \mathrm{O}_{2}+$ miR-29b-3p inhibitor group displayed increased ratio of $\mathrm{p}-\mathrm{ERK} / \mathrm{t}-\mathrm{ERK}$, 
whereas the $\mathrm{H}_{2} \mathrm{O}_{2}+$ siRNF138 group showed the opposite results. Moreover, the effect of miR-29b-3p inhibitor on the ERK pathway was significantly rescued by siRNF138.

\section{Discussion}

The loss of vision caused by glaucoma is irreversible. Multiple miRNAs are related to retinal damage, retinal homeostasis and retinogenesis $(22,23)$. Previous reports identified a series of miRNAs that may be potential biomarkers in glaucoma $(24,25)$. Additionally, oxidative stress is a key pathophysiological mechanism in glaucoma (26). The high IOP results from the imbalance of the aqueous humor inflow and outflow, and the oxidative injury of TM is responsible for aqueous humor outflow $(6,7)$. Therefore, the present study explored the role of miR-29b-3p in the oxidative injury of TM cells. miRNAs act as key regulators of TM cells in the progression of glaucoma $(15,27)$. The present study found that miR-29b-3p expression was increased in glaucoma model rats and antagomiR-29b-3p alleviated the symptoms of glaucoma. Moreover, miR-29b-3p expression was significantly upregulated in $\mathrm{H}_{2} \mathrm{O}_{2}$-stimulated HTM cells. Downregulation of miR-29b-3p alleviated $\mathrm{H}_{2} \mathrm{O}_{2}$-induced oxidative injury in HTM cells by promoting cell viability, and inhibiting cell apoptosis and ROS generation as well as ECM production. Previous studies have reported that oxidative damage aggravates glaucoma progression by increasing TM cell apoptosis and ECM production $(28,29)$. These findings suggested that inhibition of miR-29b-3p may play a protective role in glaucoma.

Based on bioinformatics analysis, RNF138 was predicted as a downstream target of miR-29b-3p. RNF138 serves as an anti-apoptotic gene in cancers. Upregulation of RNF138 promotes cell proliferation and inhibits apoptosis in cisplatin-sensitive gastric cancer cells (30). Additionally, downregulation of RNF138 induces apoptosis of spermatogenic cells in mice (31). In the present study, RNF138 was confirmed to be the functional downstream gene of miR-29b-3p. RNF138 expression was downregulated in HTM cells with $\mathrm{H}_{2} \mathrm{O}_{2}$ stimulation. Silencing of RNF138 inhibited viability, promoted apoptosis, ROS generation and ECM production in HTM cells under oxidative injury. In addition, RNF138 knockdown significantly reversed the protective effects of miR-29b-3p inhibitor on the oxidative injury in HTM cells, which was consistent with the anti-apoptotic role of RNF138 identified in previous literatures.

The ERK signaling pathway is an important intracellular pathway, which has the ability to promote proliferation in various cell types $(32,33)$. The activation of the ERK pathway induced by Vitamin D attenuates the $\mathrm{H}_{2} \mathrm{O}_{2}$-stimulated oxidativeinjury inhumanendothelialcells(34). The ERK pathway activated by myeloid cell leukemial protects rat pheochromocytoma cells from $\mathrm{H}_{2} \mathrm{O}_{2}$ oxidant injury (35). RNF138 silencing suppresses the development of glioma by repressing the ERK pathway (36). Therefore, the present study detected the changes of key proteins in the ERK pathway in HTM cells stimulated by $\mathrm{H}_{2} \mathrm{O}_{2}$. The ERK pathway was significantly suppressed in HTM cells under $\mathrm{H}_{2} \mathrm{O}_{2}$ stimulation, and this suppression was rescued by miR-29b-3p suppression. Additionally, RNF138 knockdown inhibited the activation of ERK pathway induced by miR-29b-3p knockdown.
Therefore, miR-29b-3p regulated the ERK pathway by targeting RNF138 in HTM cells under oxidative injury.

In conclusion, the present study revealed that silencing of miR-29b-3p alleviated glaucoma and suppressed apoptosis, ROS generation, ECM deposition, as well as promoting the viability of HTM cells under oxidative injury. Mechanistically, miR-29b-3p was demonstrated to target RNF138 3'UTR and downregulates its expression to inactive the ERK pathway. The protective role of silencing of miR-29b-3p in HTM cells may offer a novel therapeutic strategy for glaucoma.

\section{Acknowledgements}

Not applicable.

\section{Funding}

This study was supported by the Research Fund of Anhui Medical University (grant no. 2020xkj202).

\section{Availability of data and materials}

The datasets used and/or analyzed during the current study are available from the corresponding author on reasonable request.

\section{Authors' contributions}

HL, YX, QZ and LT performed the experiments. HL, QZ, QW, YX and LT contributed to data analysis and wrote the paper. HL and LT made substantial contributions to the design of the present study and acquired experimental materials. All authors read and approved the final manuscript. HL and LT confirm the authenticity of all the raw data.

\section{Ethics approval and consent to participate}

All animal studies were performed following the animal guidelines of the International Association for the Study of Pain, and approved by the Ethics Committee of the Second Hospital of Anhui Medical University (approval no. 2019-051; Hefei, China).

\section{Patient consent for publication}

Not applicable.

\section{Competing interests}

The authors declare that they have no competing interests.

\section{References}

1. Yanagi M, Kawasaki R, Wang JJ, Wong TY, Crowston J and Kiuchi Y: Vascular risk factors in glaucoma: A review. Clin Exp Ophthalmol 39: 252-258, 2011.

2. Liao Q, Wang DH and Sun HJ: Association of genetic polymorphisms of eNOS with glaucoma. Mol Vis 17: 153-158, 2011

3. Williams PA, Harder JM, Foxworth NE, Cochran KE, Philip VM, Porciatti V, Smithies O and John SW: Vitamin B3 modulates mitochondrial vulnerability and prevents glaucoma in aged mice. Science 355: 756-760, 2017. 
4. Heijl A, Leske MC, Bengtsson B, Hyman L, Bengtsson B and Hussein M; Early Manifest Glaucoma Trial Group: Reduction of intraocular pressure and glaucoma progression: Results from the early manifest glaucoma trial. Arch Ophthalmol 120: 1268-1279, 2002 .

5. Hysi PG, Cheng CY, Springelkamp H, Macgregor S, Bailey JNC, Wojciechowski R, Vitart V, Nag A, Hewitt AW, Höhn R, et al: Genome-wide analysis of multi-ancestry cohorts identifies new loci influencing intraocular pressure and susceptibility to glaucoma. Nat Genet 46: 1126-1130, 2014.

6. Villarreal G Jr, Oh DJ, Kang MH and Rhee DJ: Coordinated regulation of extracellular matrix synthesis by the microRNA-29 family in the trabecular meshwork. Invest Ophthalmol Vis Sci 52: 3391-3397, 2011.

7. Vidal-Sanz M, Salinas-Navarro M, Nadal-Nicolás FM, Alarcón-Martínez L, Valiente-Soriano FJ, de Imperial JM, Avilés-Trigueros M, Agudo-Barriuso M and Villegas-Pérez MP: Understanding glaucomatous damage: Anatomical and functional data from ocular hypertensive rodent retinas. Prog Retin Eye Res 31: 1-27, 2012.

8. Vranka JA, Kelley MJ, Acott TS and Keller KE: Extracellular matrix in the trabecular meshwork: Intraocular pressure regulation and dysregulation in glaucoma. Exp Eye Res 133: 112-125, 2015.

9. Medina-Ortiz WE, Belmares R, Neubauer S, Wordinger RJ and Clark AF: Cellular fibronectin expression in human trabecular meshwork and induction by transforming growth factor- $\beta 2$. Invest Ophthalmol Vis Sci 54: 6779-6788, 2013.

10. Schanen BC and $\mathrm{Li} \mathrm{X}$ : Transcriptional regulation of mammalian miRNA genes. Genomics 97: 1-6, 2011.

11. Wahid F, Khan T and Kim YY: MicroRNA and diseases: Therapeutic potential as new generation of drugs. Biochimie 104: 12-26, 2014.

12. Ha M and Kim VN: Regulation of microRNA biogenesis. Nat Rev Mol Cell Biol 15: 509-524, 2014.

13. Chen K and Rajewsky N: The evolution of gene regulation by transcription factors and microRNAs. Nat Rev Genet 8: 93-103, 2007.

14. Su W, Li Z, Jia Y, Zhu Y, Cai W, Wan P, Zhang Y, Zheng SG and Zhuo Y: MicroRNA-21a-5p/PDCD4 axis regulates mesenchyma stem cell-induced neuroprotection in acute glaucoma. J Mol Cell Biol 9: 289-301, 2017.

15. Ruibin W, Zheng X, Chen J, Zhang $X$, Yang $X$ and Lin $Y$ : Micro RNA-1298 opposes the effects of chronic oxidative stress on human trabecular meshwork cells via targeting on EIF4E3. Biomed Pharmacother 100: 349-357, 2018.

16. Shen W, Han Y, Huang B, Qi Y, Xu L, Guo R, Wang X and Wang J: MicroRNA-483-3p inhibits extracellular matrix production by targeting Smad4 in human trabecular meshwork cells. Invest Ophthalmol Vis Sci 56: 8419-8427, 2015.

17. Yang Q, Wu F, Mi Y, Wang F, Cai K, Yang X, Zhang R, Liu L, Zhang Y, Wang Y, et al: Aberrant expression of miR-29b-3p influences heart development and cardiomyocyte proliferation by targeting NOTCH2. Cell Prolif 53: e12764, 2020.

18. Wang J, Zhu M, Ye L, Chen C, She J and Song Y: MiR-29b-3p promotes particulate matter-induced inflammatory responses by regulating the C1QTNF6/AMPK pathway. Aging (Albany NY) 12: $1141-1158,2020$

19. Zeng Y, Cui Z, Liu J, Chen J and Tang S: MicroRNA-29b-3p promotes human retinal microvascular endothelial cell apoptosis via blocking SIRT1 in diabetic retinopathy. Front Physiol 10: 1621, 2019.

20. Orlans FB: Ethical decision making about animal experiments. Ethics Behav 7: 163-171, 1997.

21. Livak KJ and Schmittgen TD: Analysis of relative gene expression data using real-time quantitative PCR and the 2(-Delta Delta C(T)) method. Methods 25: 402-408, 2001
22. Izzotti A, Ceccaroli C, Longobardi MG, Micale RT, Pulliero A, La Maestra S and Saccà SC: Molecular damage in glaucoma: From anterior to posterior eye segment. Microrna 4: 3-17, 2015.

23. Genini S, Guziewicz KE, Beltran WA and Aguirre GD: Altered miRNA expression in canine retinas during normal development and in models of retinal degeneration. BMC Genomics 15: 172, 2014.

24. Hindle A, Thoonen R, Jasien JV, Grange RMH, Amin K, Wise J, Ozaki M, Ritch R, Malhotra R and Buys ES: Identification of candidate miRNA biomarkers for glaucoma. Invest Ophthalmol Vis Sci 60: 134-146, 2019.

25. Romano G, Platania CB, Forte S, Salomone S, Drago F and Bucolo C: MicroRNA target prediction in glaucoma. Prog Brain Res 220: 217-240, 2015

26. Kim KY, Perkins GA, Shim MS, Bushong E, Alcasid N, Ju S, Ellisman MH, Weinreb RN and Ju WK: DRP1 inhibition rescues retinal ganglion cells and their axons by preserving mitochondrial integrity in a mouse model of glaucoma. Cell Death Dis 6: e1839, 2015.

27. Wang Y, Li F and Wang S: MicroRNA-93 is overexpressed and induces apoptosis in glaucoma trabecular meshwork cells. Mol Med Rep 14: 5746-5750, 2016.

28. Ueda J, Wentz-Hunter K and Yue BY: Distribution of myocilin and extracellular matrix components in the juxtacanalicular tissue of human eyes. Invest Ophthalmol Vis Sci 43: 1068-1076, 2002.

29. Fatma N, Kubo E, Toris CB, Stamer WD, Camras CB and Singh DP: PRDX6 attenuates oxidative stress- and TGFbeta-induced abnormalities of human trabecular meshwork cells. Free Radic Res 43: 783-795, 2009.

30. Lu Y, Han D, Liu W, Huang R, Ou J, Chen X, Zhang X, Wang X, Li S, Wang L, et al: RNF138 confers cisplatin resistance in gastric cancer cells via activating Chk1 signaling pathway. Cancer Biol Ther 19: 1128-1138, 2018.

31. $\mathrm{Xu} \mathrm{L}$, Lu Y, Han D, Yao R, Wang H, Zhong S, Luo Y, Han R, Li K, Fu J, et al: Rnf138 deficiency promotes apoptosis of spermatogonia in juvenile male mice. Cell Death Dis 8: e2795, 2017.

32. Kim EK and Choi EJ: Compromised MAPK signaling in human diseases: An update. Arch Toxicol 89: 867-882, 2015.

33. Sun Y, Liu WZ, Liu T, Feng X, Yang N and Zhou HF: Signaling pathway of MAPK/ERK in cell proliferation, differentiation, migration, senescence and apoptosis. J Recept Signal Transduct Res 35: 600-604, 2015.

34. Polidoro L, Properzi G, Marampon F, Gravina GL, Festuccia C, Di Cesare E, Scarsella L, Ciccarelli C, Zani BM and Ferri C: Vitamin D protects human endothelial cells from $\mathrm{H}_{2} \mathrm{O}_{2}$ oxidant injury through the Mek/Erk-Sirt1 axis activation. J Cardiovasc Transl Res 6: 221-231, 2013

35. Li R, Yin F, Guo YY, Zhao KC, Ruan Q and Qi YM: Knockdown of ANRIL aggravates $\mathrm{H}_{2} \mathrm{O}_{2}$-induced injury in PC-12 cells by targeting microRNA-125a. Biomed Pharmacother 92: 952-961, 2017.

36. Wu H, Li X, Feng M, Yao L, Deng Z, Zao G, Zhou Y, Chen S and Du Z: Downregulation of RNF138 inhibits cellular proliferation, migration, invasion and EMT in glioma cells via suppression of the Erk signaling pathway. Oncol Rep 40: 3285-3296, 2018

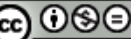

This work is licensed under a Creative Commons Attribution-NonCommercial-NoDerivatives 4.0 International (CC BY-NC-ND 4.0) License. 